\title{
PRISMATOMERIS FRAGRANS E.T. GEDDES (RUBIACEAE) - A NEW RECORD FOR THE FLORA OF VIET NAM
}

\author{
TRAN THE BACH ${ }^{1}$, BUI HONG QUANG, RITESH KUMAR CHOUDHARY ${ }^{2}$, DO VAN HAI, \\ TRAN THI NGOC DiEP ${ }^{3}$ AND JOONGKU LEE ${ }^{4}$ \\ Institute of Ecology \& Biological Resources, Viet Nam Academy of Science and Technology, 18- \\ Hoang Quoc Viet, Cau Giay, Hanoi, Viet Nam
}

Keywords: Prismatomeris; New record; Rubiaceae; Viet Nam.

Prismatomeris Thwaites is a small genus consisting of 15 species in the family Rubiaceae and is distributed throughout Asia (Mabberley, 2008; Chen and Taylor, 2011). In Viet Nam, the genus is represented by four species (Ho, 2000; Tran, 2005). While exploring the flora of HonBa Nature Reserve in Khan Hoa Province of the country, the authors came across an interesting specimen of Prismatomeris which, after critical examination and with help of relevant literature (Pitard, 1924; Ho, 2000; Tran, 2005; Chen and Taylor, 2011) and type specimens, identified as $P$. fragrans E.T. Geddes. This species was so far reported from North West Laos and Thailand, but never from Viet Nam. Hence, this is reported as a new distributional record for the flora of Viet Nam. A detailed description and colour photographs are provided for easy identification of the species.

Prismatomeris fragrans E.T. Geddes, Bull. Misc. Inform. Kew 1927(4): 173 (1927); Craib in Fl. Siam. En. 2(2): 182 (1934); Johansson, Opera Bot. 94: 42 (1987).

(Fig. 1).

Medium-sized tree, up to $12 \mathrm{~m}$ high. Bark grey, texture rough. Leaf blades coriaceous, obovate to elliptic, $6-15 \times 2-5 \mathrm{~cm}$, base cuneate, apex acute to acuminate, glabrous, margin entire; lateral veins 6-12 pairs; petioles $1-3 \mathrm{~cm}$ long; stipules caducous, $2-4 \mathrm{~mm}$ long. Inflorescence umbellate, 1-7 flowered. Flowers fragrant, pentamerous; pedicels $1.5-4 \mathrm{~cm}$ long. Calyx shortly denticulate, tube 3-4 mm long, teeth c. $1 \mathrm{~mm}$ long, with tufts of straight hairs up to $0.4 \mathrm{~mm}$ long. Corolla white, thick; tube $1.5-2.0 \mathrm{~cm}$ long and c. $2 \mathrm{~cm}$ in diameter; lobes recurved at maturity, about as long as the tube. Stamens included, inserted in the upper third to upper half of the corolla tube; filaments c. $0.5-2.5 \mathrm{~mm}$ long; anthers c. $4-5 \mathrm{~mm}$ long. Ovary up to $1 \mathrm{~mm}$ long, glabrous; style 7(-14) mm long, stigmas 3(-5) $\mathrm{mm}$ long. Drupe green, shiny black when mature, subglobose, c. $1 \mathrm{~cm}$ in diameter.

Flowering period: April. Fruiting period: May to June.

Specimens examined: Viet Nam: Khanh Hoa Province; Hon Ba Nature Reserve, 9 Apr 2011, J. Lee et al. HIKK-008; l.c., You-Mi, Lee et al., 10 Apr 2011, HIKK-254; HIKK-371 (HN, KRIB). Thailand: Chon Buri (Si Racha, Ban Dan, lectotype: Marcan 1381, K-Photo!, BM), Rayong, Chanthaburi.

Distribution: North-West Laos, Thailand (Puff et al., 2005), and Viet Nam.

\footnotetext{
${ }^{1}$ Duy Tan University, Da Nang Province, Viet Nam \& IEBR, VAST, Viet Nam.

${ }^{2}$ Agharkar Research Institute, Biodiversity \& Palaeobiolgy Group, G.G. Agarkar Road, Pune 411 004, India.

${ }^{3}$ Hung Vuong University, Nong Trang Ward, Viet Tri City, Phu Tho Province, Viet Nam.

${ }^{4}$ Corresponding author. Department of Environment \& Forest Resources, Chungnam National University, 99

Daehak-ro, Daejon 34134, South Korea. Email: joongku@cnu.ac.kr
} 


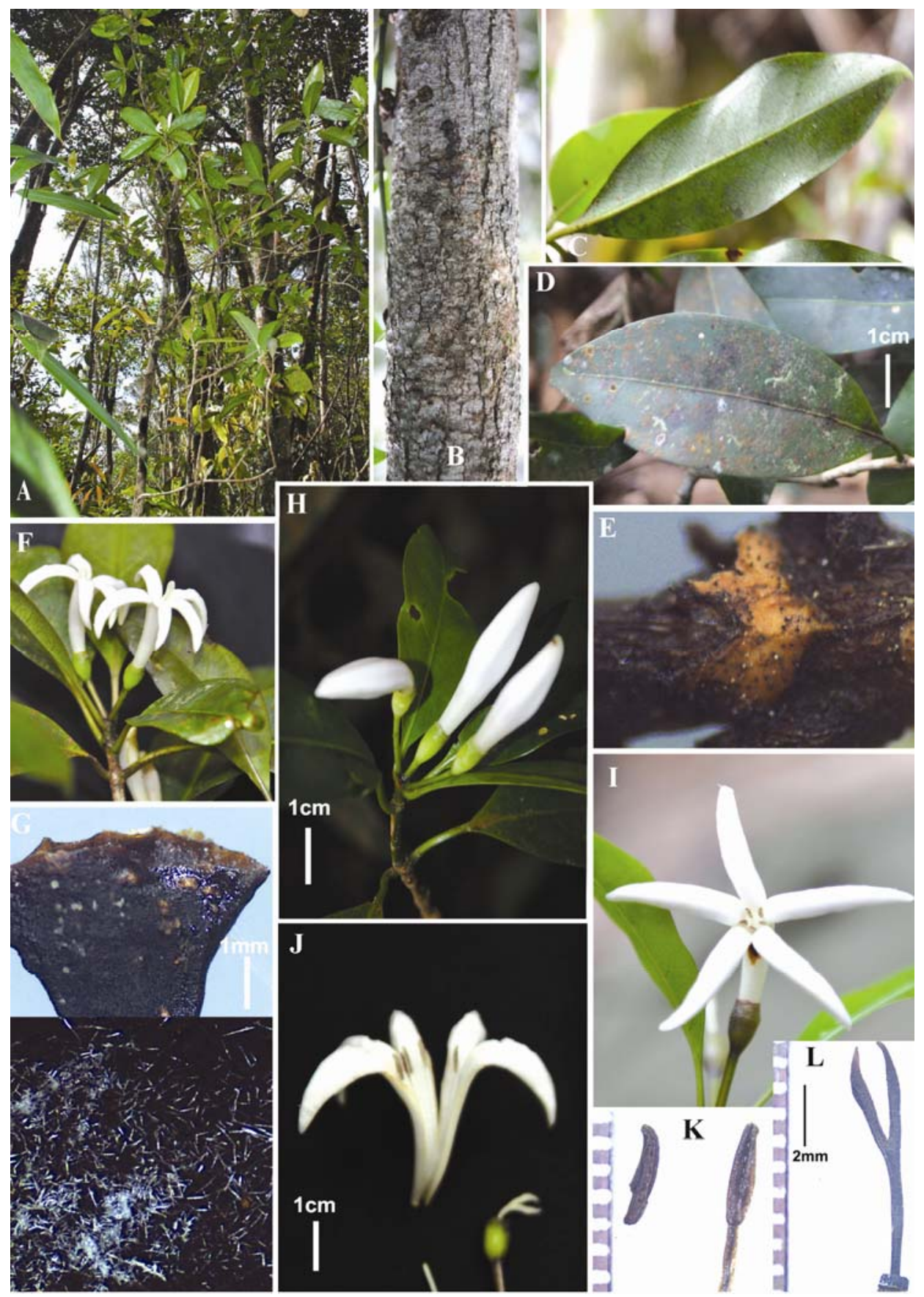

Fig. 1. Prismatomeris fragrans E.T. Geddes A. Habit; B. Bark; C, D. Abaxial and adaxial portion of leaf; E. Stipules; F. Inflorescence; G. Calyx (top) with tufts of straight hairs (bottom); H. Flower buds; I. Corolla lobes; J. Corolla tube; K. Anther and filament; L. Ovary, style and stigma. 
Habitat: Exposed hillocks (800-1000 m above sea level); semi-evergreen forests.

Note: Prismatomeris fragrans is morphologically close to $P$. memecyloides Craib and $P$. filamentosa Craib by its distinctly pedicellate flowers, but different in having denticulate calyx with tuft of hairs.

Uses: The plant is also known for its medicinal properties. In Thailand, decoction of root is traditionally used by the ethnic communities to cure kidney dysfunctions (Wongsatit et al., 2002). Moreover, potential antimalarial, antifungal and anti-tuberculosis bio-chemicals have also been isolated from the plant (Kanokmedhakul et al., 2005).

Conservation status: Authors could observe only 10-15 individuals growing well within the reaches of Hon Ba Nature Reserve of Viet Nam. They were under the close monitoring of forest officials and hence, no immediate threat to the population could be seen. In Thailand, the plant has been reported from the northern, north-eastern, eastern and south eastern areas (Puff et al., 2005). In Laos, it is known only from the north-western part. However, quantitative population data of this taxon could not be found, preventing assessment under any specific criteria. Therefore, we recommend this to be kept under Data Deficient (DD) category of IUCN Red List (IUCN, 2012).

\section{Acknowledgements}

Funding support received from Viet Nam National Foundation for Science and Technology Development (NAFOSTED) vide grant number 106.11-2012.37 and Korea National Arboretum for this study is greatly acknowledged. Logistic support provided by the forest administration of Hon $\mathrm{Ba}$ Nature Reserve is also acknowledged.

\section{References}

Chen, T. and Taylor, C.M. 2011. Prismatomeris. In: Zhengyi, W., Raven, P.H. and Hong, D. (Eds), Flora of China, Vol. 19. Science Press (Beijing) \& MBG Press, Missouri, pp. 64.

Ho, P.H. 2000. Rubiaceae. In: Cay Co Viet Nam (An illustrated flora of Vietnam). Vol. 3. Nha Xuat Ban Tre, TP. Ho Chi Minh, Vietnam, pp. 217-218. [in Vietnamese]

IUCN 2012. Guidelines for Application of IUCN Red List Criteria at Regional and National Levels: Version 4.0. Gland, Switzerland and Cambridge, UK, iii +41 pp.

Kanokmedhakul, K., Kanokmedhakul, S. and Phatchana, R. 2005. Biological activity of Anthraquinones and Triterpenoids from Prismatomeris fragrans. J. Ethnopharmacol. 100(3): 284-288.

Mabberley, D.J. 2008. Mabberley's Plant Book: A portable Dictionary of Plants, their Classifications, and Uses. Cambridge University Press, UK, 1040 pp.

Pitard, J. 1924. Rubiaceae In: Lecomte, M.H. (Ed.), Flore Générale de L’Indochine, Vol. 3. Masson et Cie, Paris, pp. 427-430.

Puff, C., Chayamarit, K. and Chamchumroon, V. 2005. Rubiaceae of Thailand. A pictorial guide to indigenous and cultivated genera. The Forest Herbarium, National Park, Wildlife and Plant Conservation Department, Bangkok, 245 pp.

Tran, N.N. 2005. Rubiaceae. In: Ban, N.T., Khoi, N.K. and Phuong, V.X. (Eds), Checklist of Plant Species of Vietnam, Vol. 3. Vietnamese Acad. Sci. Technol., Missouri Bot. Garden \& Hanoi Nat. Univ., Agri. Publ. House, Hanoi, pp. 192-193.

Wongsatit, C., Promchit, S. and Boonpleng, A. 2002. Medicinal plants used in the Loengnoktha district, Yasothon Province, Thailand. Thai J. Phytopharmacy 9(2): 24-46. 